\title{
Flash Drought as Captured by Reanalysis Data: Disentangling the Contributions of Precipitation Deficit and Excess Evapotranspiration
}

\author{
R. D. KOSTER \\ Global Modeling and Assimilation Office, NASA GSFC, Greenbelt, Maryland
}

S. D. SCHUBERT

Global Modeling and Assimilation Office, NASA GSFC, Greenbelt, and Science Systems and Applications, Inc., Lanham, Maryland

\author{
H. WANG
}

Science Systems and Applications, Inc., Lanham, Maryland

S. P. MAHANAMA

Global Modeling and Assimilation Office, NASA GSFC, Greenbelt, and Science Systems and Applications, Inc., Lanham, Maryland

\author{
ANTHONy M. DEANGELIS
}

Science Systems and Applications, Inc., Lanham, Maryland

(Manuscript received 19 November 2018, in final form 22 February 2019)

\begin{abstract}
Flash droughts - uncharacteristically rapid dryings of the land system — are naturally associated with extreme precipitation deficits. Such precipitation deficits, however, do not tell the whole story, for land surface drying can be exacerbated by anomalously high evapotranspiration (ET) rates driven by anomalously high temperatures (e.g., during heat waves), anomalously high incoming radiation (e.g., from reduced cloudiness), and other meteorological anomalies. In this study, the relative contributions of precipitation and ET anomalies to flash drought generation in the Northern Hemisphere are quantified through the analysis of diagnostic fields contained within the MERRA-2 reanalysis product. Unique to the approach is the explicit treatment of soil moisture impacts on ET through relationships diagnosed from the reanalysis data; under this treatment, an ET anomaly that is negative relative to the local long-term climatological mean is still considered positive in terms of its contribution to a flash drought if it is high for the concurrent value of soil moisture. Maps produced in the analysis show the fraction of flash drought production stemming specifically from ET anomalies and illustrate how ET anomalies for some droughts are related to temperature and radiation anomalies. While ET is found to have an important impact on flash drought production in the central United States and in parts of Russia known from past studies to be prone to heat wave-related drought, and while this impact does appear stronger during the onset (first several days) of flash droughts, overall the contribution of ET to these droughts is small relative to the contribution of precipitation deficit.
\end{abstract}

\section{Introduction}

\section{a. Drivers of flash drought}

In the simplest terms, a region experiencing drought is a region experiencing a significant water deficit. The different "flavors" of drought can also easily, if imprecisely,

Corresponding author: Randal Koster, randal.d.koster@nasa.gov be described: meteorological drought is, in essence, a long-term precipitation deficit, agricultural drought focuses on resulting soil moisture deficits and their impacts on vegetation (e.g., crop) stress, hydrological drought focuses on associated water deficits in rivers and reservoirs, and socioeconomic drought relates water deficits to societal water needs. Such simple descriptions, of course, belie the tremendous complexity of drought phenomena. Despite substantial research and moderate 
progress in analyzing the mechanisms underlying the formation, maintenance, and senescence of droughts [see Wood et al. (2015) and Schubert et al. (2016) for recent reviews], our understanding of drought and its different manifestations is still limited, and our ability to predict a drought, say, months in advance remains a major challenge, particularly during the warm season. An improved understanding of droughts and an improved ability to predict them would have substantial societal benefit, and this naturally makes drought an active focus of research, with analyses coordinated through, for example, the WCRP Drought Interest Group (Legler and Pirani 2009) and the NOAA Drought Task Force (Mariotti et al. 2013).

Introduced relatively recently into the scientific vernacular is the concept of the "flash drought" (Svoboda et al. 2002) - a drought that develops unusually quickly. Otkin et al. (2018), who provide a recent overview article on the subject (which includes a full literature review), define flash droughts as "a subset of all droughts that are distinguished from more conventional slowly developing droughts by their unusually rapid rate of intensification." They apply the term, for example, to the 2012 drought in the central United States and show, as a tangible illustration, how vegetation in central Oklahoma went from a healthy green state to a brown dormancy over a period of 6 weeks, in sharp contrast to what is normally seen in the area. The continental United States has in fact seen a spate of such droughts in recent years, giving the concept considerable and growing attention.

Why would a drought develop more quickly than usual? Considering soil moisture as a proxy for the moisture state of the land-atmosphere system (focusing, that is, on agricultural drought rather than on meteorological drought), two drivers of drought seem clear: anomalously low precipitation (a reduced water source) and anomalously high evapotranspiration (ET; an increased water sink). However, while precipitation's role in the development of a drought is intuitive, that played by ET is rather complex. Otkin et al. (2018), in their description of a typical flash drought event, point to high ET as a potential initial driver of an event but note the complication that ET will decrease later in the event in conjunction with deteriorating vegetation as the soil dries. Hobbins et al. (2016) point out that such behavior is associated with a shift from energy-limited to water-limited conditions, and they introduce an evapotranspiration-based drought index that works in both regimes. Such indices (see also Otkin et al. 2013) should be valuable for the identification and monitoring of conditions favorable to fast-developing agricultural droughts.
The difficulties in quantifying ET's role in driving flash drought can be considered in the context of landatmosphere feedbacks between soil moisture and overlying meteorological conditions. Consider, for example, heat waves, which at first glance may be expected to promote soil drying given that higher temperatures generally lead to higher ET. Mo and Lettenmaier (2015, 2016) point out that heat waves do not always induce drying - the presence of a heat wave does not, in and of itself, indicate that ET is helping to produce drought conditions. While ET may contribute to a flash drought in the case of an externally produced heat wave (e.g., the advection of remote warm air into a region), a heat wave may instead simply be a local passive response to a precipitation deficit, given that the reduced ET associated with drier soils leads to reduced evaporative cooling. (Of course, a heat wave may be deemed a drought driver if it develops before, rather than during, the production of a drought.) Such land-atmosphere feedbacks (see also, e.g., Seneviratne et al. 2010; Berg et al. 2014; Schwingshackl et al. 2018) similarly complicate the interpretation of dry overlying air as a driver of drought. While drier air ostensibly promotes higher ET, such dryness may instead be nothing more than a passive response to a low ET induced by a precipitation deficit. Potential land-atmosphere feedbacks on other potentially important atmospheric drivers (e.g., incoming radiation and wind speed) are not as obvious but perhaps may still be relevant.

\section{b. Quantifying and analyzing flash drought with reanalysis data}

An atmospheric reanalysis (CCSP 2008) is, in essence, a mathematically optimal merging of observations and Earth system model physics that results in spatially and temporally comprehensive quantitative estimates of atmospheric and land surface variables across the globe. The input observations are generally extensive, and the modeled physical formulations impart appropriate physical behaviors to the variables considered (as captured, for example, by equations of motion and conservation laws); as a result, reanalyses products are considered by many to be the best description of global scale meteorological fields available. Applications of reanalysis data to climate problems has indeed been extensive, as immediately evident from the thousands of journal articles citing the small handful of global scale products offered to the community (e.g., the products described by Kanamitsu et al. 2002; Dee et al. 2011; Rienecker et al. 2011; Kobayashi et al. 2015; Gelaro et al. 2017).

The idea examined here is that reanalysis data may be of value for analyzing and understanding the drivers of flash drought. Reanalysis products include estimates of 
relevant meteorological forcing variables such as precipitation, evapotranspiration, air temperature, air humidity, wind speed, and incident radiation. The products also include soil moisture estimates that are consistent with these variables, allowing the quantification of relationships between soil moisture and meteorological drivers. Most reanalyses provide several decades of data and thus can provide data for multiple flash droughts in a given region of interest.

Any flash drought analysis using reanalysis data, however, must be considered in light of two very important considerations. First, because soil moisture observations are rarely, if ever, assimilated directly into reanalysis systems, the connections between reanalysis soil moisture and atmospheric forcing variables are largely dependent on the imposed land surface model formulations, and accordingly, the land fluxes and states produced in a reanalysis will have geographically and seasonally varying biases. The presumed biases stem from the fact that the land surface formulations - particularly the control of soil moisture content on evapotranspiration - cannot be adequately validated against observations, as the required data at the large scale do not exist. Soil moisture estimates at the large scale are particularly elusive; site level measurements of soil moisture through the root zone cannot be assumed to represent large scale averages, and satellite-based soil moisture values (e.g., Kerr et al. 2010; Entekhabi et al. 2010) represent, at most, the top few centimeters of soil. Measurements of large-scale soil moisture averages, even if they did exist, could only be used in validating model formulations if contemporaneous evapotranspiration measurements of sufficient accuracy were also available for the large-scale region over a substantial length of time, and, of course, evapotranspiration estimates from flux towers or from satellite-based algorithms (e.g., Anderson et al. 2011) come with their own sets of spatial scales, uncertainties, and assumptions. Complicating validation further is the inherently modeldependent character of simulated soil moisture (Koster et al.2009), which is largely unavoidable given the need to parameterize hydrological processes that cannot be spatially resolved (soil moisture in nature varies spatially within a gridcell area, and hydrological processes such as runoff vary nonlinearly with soil moisture) and given the absence of high-resolution data on soil properties.

Assuming, however, that the model formulations have sensible forms that agree qualitatively with the relationships operating in nature, a reanalysis-based study of flash drought can provide critical insights into the phenomenon-in particular, into how the different meteorological drivers can interact to produce or mitigate the drought. This is the level of analysis attempted here. The unique contribution of the present study is an illustration of how evapotranspiration varies both with soil moisture and with external meteorological drivers and how it is the latter variation that should be isolated and utilized when quantifying the contribution of evapotranspiration excess to drought - a facet of the science that, in the literature, is generally not acknowledged. We will, as a matter of course, produce quantitative estimates of drought frequency and of the relative contributions of precipitation deficit and evapotranspiration excess to flash drought formation, and while we expect these estimates to be reasonable, at least to first order, the precise magnitudes of the estimates will nonetheless reflect the land surface model formulations underlying the reanalysis system. Confirmation of our estimates-or more correctly, a quantification of the uncertainty in our estimates-must await a repeat of the analysis with other systems.

The second important consideration in a reanalysisbased study of flash drought is the advantage of having enough data to identify a flash drought with a well-defined quantitative metric. We can thus avoid ambiguities that might arise from a more subjective identification of such droughts. This said, the droughts identified with any given metric may miss certain events recognized in the literature as being flash droughts, as these missed events may have been classified using an alternative (and sometimes more subjective) approach, perhaps involving agricultural or economic indicators. In the present paper, we choose a single, hydrology-based quantitative metric to define flash drought, recognizing that other definitions would affect the estimates we compute and the distributions we plot.

These two considerations underline the fact that this study is not presented here as the final word on flash drought. Again, our goal is to use reanalysis data to illustrate a new and complementary way of looking at the phenomenon, one that emphasizes the separation of an ET anomaly during a diagnosed flash drought period into two parts: one that directly reflects the impacts of the soil moisture state (drier soils produce lower ET) and one that captures the remaining impacts associated with the overlying meteorology, effectively correcting them for the soil moisture impacts. The approach thus explicitly addresses many of the complications imposed on the problem by land-atmosphere feedback. We use the approach to produce global maps showing, for our chosen drought definition and reanalysis product, how the relative contributions of precipitation deficits and ET anomalies to flash drought vary across North America and the Northern Hemisphere. In addition to elucidating the connection between flash drought and evapotranspiration, we present the study to encourage further analyses with other reanalysis datasets and other flash drought definitions. 
Section 2 below provides a description of the data analyzed, the definition of flash drought used in this study, and the strategy employed for separating the precipitation and ET contributions to these droughts. Results are provided in section 3, followed by discussion and conclusions in section 4 .

\section{Approach}

\section{a. Data source: The MERRA-2 reanalysis}

MERRA-2 (Bosilovich et al. 2015; Gelaro et al. 2017) is a state-of-the-art atmospheric reanalysis that blends satellite and more conventional weather observations with modeled atmospheric behavior in an attempt to produce the best possible estimates of the Earth system (atmospheric and land surface) state over the satellite era. MERRA-2 fields are comprehensive in space, covering the globe at a $0.5^{\circ}$ latitude $\times 0.625^{\circ}$ longitude spatial resolution and with 72 hybrid-eta levels in the vertical, up to $0.01 \mathrm{hPa}$. Coverage in time is also comprehensive, with hourly fields available for the period 1979-present, though here we utilize daily fields and the period 1980-2017. MERRA-2 assimilates a substantial number of satellite-based observations (McCarty et al. 2016) and is unique among modern reanalyses in its inclusion of aerosol data assimilation (Randles et al. 2016). The accuracy of MERRA-2 data has been evaluated extensively (Bosilovich et al. 2015; Gelaro et al. 2017).

For the present analysis we examine MERRA-2 daily fields of root-zone soil moisture $W$ (dimensionless units of degree of saturation, representing moisture in the top meter of soil), precipitation $P\left(\mathrm{~mm} \mathrm{day}^{-1}\right)$, total ET $\left(\mathrm{mm} \mathrm{day}^{-1}\right)$, incoming solar radiation $\left(\mathrm{SW} ; \mathrm{W} \mathrm{m}^{-2}\right)$, and $2-\mathrm{m}$ air temperature $(\mathrm{T} 2 \mathrm{M} ; \mathrm{K})$. As described in the next section, flash drought will be defined as a rapid decrease in $W$ in conjunction with subsequent evaporative stress. We will analyze such decreases in terms of anomalies in $P$ and ET.

It is important to note here that the MERRA-2 reanalysis has, in effect, two precipitation products: a base product generated by the model underlying the reanalysis, and a "corrected" product in which the base product was scaled to agree with precipitation gauge measurements (Reichle et al. 2017a). The precipitation used to force the land surface during the reanalysis itself was, in fact, the latter (corrected) version. The reanalysis's ET fields, like its $W$ fields, are thus strongly guided by the incident observed precipitation. The corrected model precipitation product is also examined directly in the analyses below. Because we are interested in the liquid water contribution to the soil, we reduce each daily precipitation flux by the contemporaneous snowfall flux and augment it by the daily snowmelt flux; given that we focus on the warm season (see below), this modification should have little impact on our results.

The land surface model used in the reanalysis is the Catchment model of Koster et al. (2000). Evapotranspiration is computed in this model as part of a full energy balance calculation at the land surface; it thus responds directly to variations in incoming radiative energy, air temperature, wind speed, and humidity while accounting at the same time for soil moisture state. As noted in section $1 \mathrm{~b}$, the underlying, effective relationship in this model (as in any model) between evapotranspiration and soil moisture cannot be validated against observations given a lack of adequate large-scale data. The qualitative character of the relationship, however-the increase of ET with soil moisture at the dry end and the plateauing of the relationship at the wet end-is fully consistent with that established from observations at a point (e.g., Salvucci 2001; Dirmeyer et al. 2006) and with longstanding conceptual understanding of how evapotranspiration behaves (e.g., Manabe 1969; Eagleson 1978). (See section $2 \mathrm{c}$ for further discussion.) We thus deem it suitable for our own conceptual analysis. Note, however, that the treatment of vegetation in MERRA-2 is fairly simple, with phenological variables prescribed every year to climatological seasonal cycles; interannual variability in vegetation structure is thus absent and not allowed to affect the soil moisture-evapotranspiration relationship. Evaluations of the hydrological and energy cycles at the land surface in MERRA-2 are provided by Reichle et al. (2017b) and Draper et al. (2018), respectively.

Another caveat that should be mentioned involves a problem seen in many reanalyses, namely, the presence of discontinuities in the reanalysis record associated with changes in the observing system. In the context of land hydrology and thus our own analysis, the use of gauge-based precipitation corrections throughout the MERRA-2 period reduces this problem. Nevertheless, such discontinuities may still have an impact on the temperatures and humidities that force evapotranspiration in the system.

\section{b. Definition of flash drought}

The definition of flash drought used here follows that suggested by Ford and Labosier (2017), which is based on soil moisture percentiles-they define a flash drought at a given location as a reduction in soil moisture from above its 40th percentile value to below its 20th percentile value over a period of 20 days. They chose the 20th percentile for the lower threshold because it corresponds to the definition of moderate drought in the U.S. Drought Monitor (Svoboda et al. 2002); the upper threshold basically represents nondrought soil moisture 
conditions. Twenty days was considered to represent well a typical subseasonal-scale flash drought generation period. Though one could argue that the relevant generation period for a flash drought might be different in different regions or in different climate regimes, here we will assume, for simplicity, that the 20-day period applies across the globe. Note that here, in contrast to Ford and Labosier (2017), we do not explicitly exclude flash droughts that occur within larger droughts.

For this study we construct soil moisture percentiles on a daily basis from the MERRA-2 root-zone soil moisture product. For a given location $j$ and a given day of year $k$, we construct a cumulative distribution function (CDF) of root-zone soil moisture from 190 values: the soil moisture at location $j$ on days $k-6, k-3, k$, $k+3$, and $k+6$ from each of the 38 years during 1980 2017. The CDFs thus vary regionally (weighted toward lower values, for example, in the western United States) and seasonally (e.g., weighted toward higher values just after the snowmelt season). Five sampling dates are chosen each year in an attempt to reduce noise, essentially through a temporal smoothing. The closeness of the dates within a given year and the typically slow evolution of root zone moisture, however, implies that the CDFs are generally based on about 38 fully independent values, though perhaps more in areas where this moisture varies significantly on weekly time scales. As constructed, the CDFs allow the immediate transformation of any MERRA-2 soil moisture value into a soil moisture percentile for use in flash drought determination.

In processing the MERRA-2 data, we found it necessary to add some additional, practical constraints to the flash drought definition. First, a drought event has to lead to at least a nominal reduction in ET and thereby reflect some moisture stress on the land system. (Note that in particularly wet areas, a reduction of ET is not guaranteed by a reduction in soil moisture percentile, given that the 20th percentile soil moisture in such areas can still be very wet. See further discussion in section 2c.) The "nominal reduction" enforced here focuses on ET in the 20 days prior and in the 20 days after the 20-day soil moisture reduction period-ET in the prior period must lie at or above four-fifths of the climatological mean value for that time of year (representing reasonably unstressed conditions prior to drought onset), and ET in the latter period must lie at or below threefifths of the climatological mean value for that later time of year. As a second constraint, independence of drought events is ensured by not allowing identified drought events (in fact, not allowing the 60 days associated with the event, namely, the 20 days of the event itself and the 20 days before and after, over which ET is computed) to overlap in time.
The final constraint is that the climatological ET during the 20-day soil moisture reduction period lies above $0.5 \mathrm{~mm}$ day $^{-1}$. This condition is imposed because in very dry regions, the range over which soil moistures vary is highly limited, implying that small anomalies in precipitation or evapotranspiration lead to small changes in soil moisture but very large changes in soil moisture percentile. Simply put, soil moisture percentile in dry regions is overly sensitive to meteorological drivers. For the purposes of this study, we avoid to a large extent this oversensitivity and the associated ambiguities in drought identification by focusing on regions and seasons that are wet enough to support a $0.5 \mathrm{~mm} \mathrm{day}^{-1}$ climatological evapotranspiration. Analysis of flash drought in drier regions is left for future work.

While the precise values of the thresholds above are, of course, somewhat arbitrary, they can be considered representative-results obtained with modified values were tested [by Ford and Labosier (2017) and by us] and found to provide qualitatively the same insights into the nature of flash drought. We focus our flash drought analysis on the boreal warm season in the Northern Hemisphere, namely, April-September, as the warm season is when evapotranspiration anomalies are most likely to contribute to such a drought. We look mainly at drought in the continental United States but also provide global results for further context.

\section{c. Assumed contributors to drought}

Simple water balance considerations require that

$$
C \frac{\Delta W}{\Delta t}=P-Q-\mathrm{ET} .
$$

Here, $C$ is the water holding capacity of the root zone (equivalent to the soil porosity multiplied by the assumed 1-m root zone depth), $\Delta W$ is the change in rootzone soil moisture (degree of saturation) over the time period $\Delta t, P$ is the precipitation rate, and ET is the evapotranspiration rate. The term $Q$ is in effect the sum of the surface runoff and gravitational drainage rates out of the root zone. Computing the 20-day mean values (at a given time of year) of each term in (1) for each year in a multidecadal record and then taking the time mean of these 20-day values produces the climatological analog:

$$
C \frac{\overline{\Delta W}}{\Delta t}=\bar{P}-\bar{Q}-\overline{\mathrm{ET}},
$$

where an overbar indicates a climatological mean. Subtracting (2) from (1) gives

$$
C \frac{\Delta W}{\Delta t}-C \frac{\overline{\Delta W}}{\Delta t}=C \frac{\Delta W^{\prime}}{\Delta t}=P^{\prime}-Q^{\prime}-\mathrm{ET}^{\prime}
$$




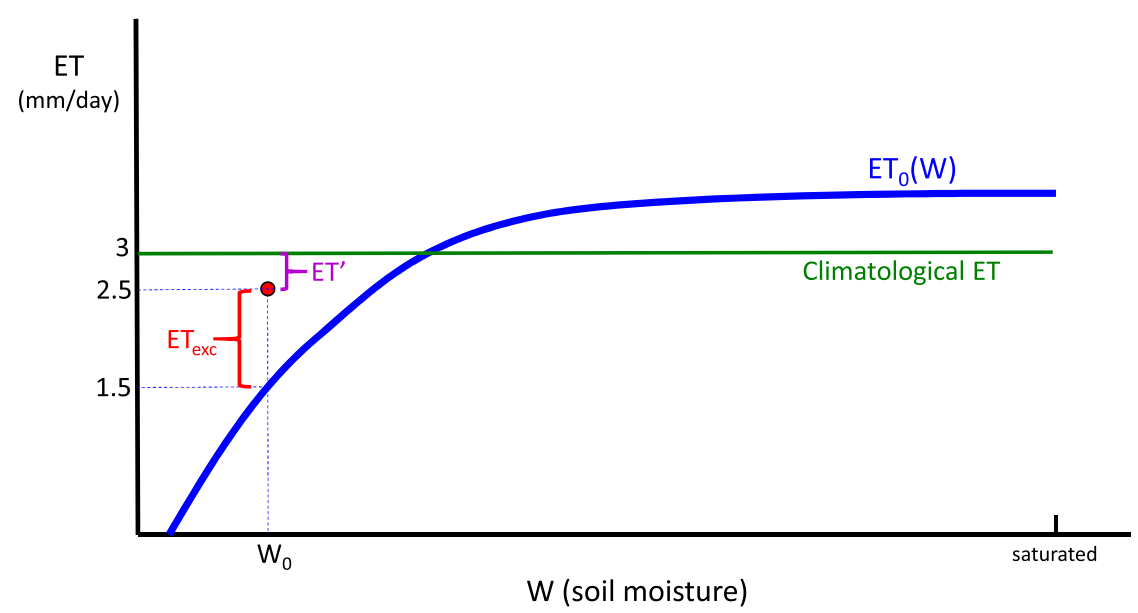

FIG. 1. Idealized representation (blue curve) of the average relationship between soil moisture $W$ and ET at a given location and time of year. The green line represents the climatological ET for the location and time of year, and the red dot shows one possible value of ET $\left(2.5 \mathrm{~mm} \mathrm{day}^{-1}\right)$ at a time when the soil moisture has a value of $W_{0}$. The red dot thus represents a situation in which the ET is lower than the climatological value (by ET') and yet higher (by $\mathrm{ET}_{\text {exc }}$ ) than the value expected for $W_{0}$, perhaps due to a positive solar radiation anomaly or air temperature anomaly.

where the prime represents an anomaly from climatology. Consider, for example, a region that typically experiences a drying during June $(\overline{\Delta W} / \Delta t<0)$ because climatologically, $\overline{\mathrm{ET}}$ for June exceeds $\bar{P}-\bar{Q}$. In such a region, the soil moisture dries even if $\Delta W^{\prime} / \Delta t=0$. A negative value of $\Delta W^{\prime} / \Delta t$, however, for June of a particular year would indicate that the root zone during that June dries even faster than it usually does.

As noted above, definitions of flash drought are largely subjective. It seems safe to posit, though, that any definition of flash drought involving soil moisture would require an anomalously fast drying of the soil and thus a negative value of $\Delta W^{\prime} / \Delta t$. The percentile-based flash drought definition provided in section $2 b$ is particularly amenable to such an interpretation. A climatological amount of soil water change $\left(\Delta W^{\prime} / \Delta t=0\right)$ during the time period would allow the soil moisture, despite getting drier or wetter in absolute terms, to maintain its percentile value for the given time of year. A percentile decrease, however, is consistent with a negative $\Delta W^{\prime} / \Delta t$.

With this in mind, (3) suggests that a flash drought could be induced by deficient precipitation (negative $P^{\prime}$ ), excessive ET (positive $\mathrm{ET}^{\prime}$ ), and/or excessive runoff (positive $Q^{\prime}$ ). In the present study we focus only on the first two terms, as these terms are somewhat independently determined by meteorological variations. Precipitation's connection to meteorology is straightforward, and while ET responds to precipitation variations, it also responds strongly to variations in air temperature, incident radiation, humidity, and wind speed. In contrast, in terms of forcing, variations in $Q$ are mostly tied to those in
$P$ and are much less affected by independent meteorological variables.

The 38 years of MERRA-2 gauge-corrected precipitation data allow for the construction, at each MERRA-2 grid cell, of a daily precipitation climatology, and for any given 20-day period, an associated precipitation anomaly $P^{\prime}$ can be computed from MERRA-2 data. A flash drought identified for the period might thus be related to a negative $P^{\prime}$ calculated for the period. In the same way, MERRA-2 data could be processed into $\mathrm{ET}^{\prime}$ anomalies. In the present analysis, however, we do not actually focus on $\mathrm{ET}^{\prime}$ as defined above, as it is not considered the evapotranspiration forcing of greatest relevance to the production of flash drought. Instead, we consider an ET forcing that is conditioned on soil moisture, as now described.

Consider Fig. 1, which shows, with the blue curve, a standard vision of how evapotranspiration varies with soil moisture. At low soil moisture values, soil moisture availability limits ET. Drier soils hold on to soil moisture more forcefully, and as a result, at the dry end, a decrease in soil moisture leads to an ET decrease. At the wet end of the soil moisture range, however, soil moisture availability is no longer the bottleneck; instead, the primary limiting factor is the atmosphere's ability to take up moisture. At these higher levels, variations in soil moisture no longer lead to corresponding variations in ET, and the relationship plateaus to a flat line. The character of this relationship has been discussed extensively in the literature, sometimes with ET normalized by a potential evaporation or a net incoming radiative 
energy flux (Manabe 1969; Eagleson 1978; Dirmeyer et al. 2006; Koster and Mahanama 2012) and sometimes without such normalization (e.g., Salvucci 2001).

Of course, in nature (as well as in models of nature, including the land model used in MERRA-2), ET depends on more than just soil moisture, even at the drier end. An actual plot of ET versus $W$ would show substantial scatter around all sections of the blue curve, for the blue curve in fact represents an "average relationship" between $W$ and ET, one that could be derived for a given time and location, for example, through data binning. (See the upcoming example in section 3a.) The existing scatter is particularly high when ET is not normalized by an incoming energy or a potential evaporation (as in Anderson et al. 2007), as even drier soils will evaporate more moisture when faced, for example, with increased incoming radiation.

With this in mind, consider the red dot in Fig. 1, which lies well above the blue curve. For the (idealized) location and day of year considered here, a soil moisture of $W_{0}$ would produce, on average, an ET of $1.5 \mathrm{~mm} \mathrm{day}^{-1}$. However, in this example, ET on the day in question was actually $2.5 \mathrm{~mm} \mathrm{day}^{-1}$ due, say, to higher-than-average solar radiation. Now consider the green line in the plot, which represents the climatological value of ET at this location and time of year; soil moistures here (considered over many years) tend to be much wetter than $W_{0}$, bringing the climatological ET to $3 \mathrm{~mm} \mathrm{day}^{-1}$. The red dot lies below the green line, meaning that $\mathrm{ET}^{\prime}$ in (3) would be negative, at $-0.5 \mathrm{~mm} \mathrm{day}^{-1}$. If, however, we condition the climatological ET on the current value of soil moisture, the anomaly of ET is positive, at $1 \mathrm{~mm} \mathrm{day}^{-1}$; ET is higher than what that particular soil moisture would normally allow. That is, while $\mathrm{ET}^{\prime}$ as defined for (3) is negative, the evaporation anomaly conditioned on soil moisture content $\left(\mathrm{ET}_{\mathrm{exc}}\right.$, the evaporation excess) can be positive:

$$
\mathrm{ET}_{\mathrm{exc}}=\mathrm{ET}-\mathrm{ET}_{0}(W),
$$

where $\mathrm{ET}_{0}$ is the average $\mathrm{ET}-W$ relationship captured with the blue curve.

With $E_{\text {exc }}$ so defined, and recalling that $\mathrm{ET}^{\prime}=\mathrm{ET}-\overline{\mathrm{ET}}$, we can rewrite (3) as

$$
C \frac{\Delta W^{\prime}}{\Delta t}=P^{\prime}-Q^{\prime}-\left[\mathrm{ET}_{0}(W)-\overline{\mathrm{ET}}\right]-\mathrm{ET}_{\mathrm{exc}},
$$

where the evapotranspiration contribution to an anomalous change in water storage is now divided into two distinct terms: (i) $\left[\mathrm{ET}_{0}(W)-\overline{\mathrm{ET}}\right]$, representing, based on the climatological ET- $W$ relationship, the anomaly in ET strictly associated with a soil moisture anomaly (i.e., representing, for example, the fact that ET tends to decrease with $W$ during droughts; in Fig. 1, this difference is the distance between the blue and green curves at a given soil moisture value), and (ii) $\mathrm{ET}_{\mathrm{exc}}$, representing the anomaly of ET relative to the ET- $W$ relationship, capturing non-soil-moisture impacts on ET. We consider $\mathrm{ET}_{\text {exc }}$ rather than $\mathrm{ET}^{\prime}$ in our flash drought analysis because it better represents the ability of anomalies in radiation, air temperature, and other meteorological forcing variables to affect the drying of the soil. In essence, the use of $\mathrm{ET}_{\mathrm{exc}}$ allows meteorological controls on ET to be isolated, to first order, from soil moisture controls, the latter of which can be strongly dominant during dry conditions. This approach indeed avoids complications in interpretation associated with the fact that slow ( $\sim$ monthly) time scales of soil moisture imprint themselves on $\mathrm{ET}^{\prime}$; by comparing $P^{\prime}$ to $\mathrm{ET}_{\text {exc }}$ rather than to $\mathrm{ET}^{\prime}$, we effectively compare drought drivers that act on similar time scales. Of course, the air temperature and radiation variations that underlie $\mathrm{ET}_{\mathrm{exc}}$ are themselves not fully independent of soil moisture; such connections will be addressed further in section 3 .

MERRA-2 evapotranspiration and soil moisture data can be analyzed jointly to produce $\mathrm{ET}_{\mathrm{exc}}$ values for any given flash drought identified in the record. The $\mathrm{ET}_{\mathrm{exc}}$ so computed can then be considered side by side with $P^{\prime}$ to quantify the relative contributions of precipitation and (meteorology-driven) evapotranspiration anomalies to that drought. A full example calculation is provided in section $3 a$.

\section{Results}

\section{a. Example of a flash drought calculation}

In this subsection we illustrate the calculations behind our flash drought determination procedure with a representative example: a 2000 flash drought identified for a grid cell $\left(36^{\circ} \mathrm{N}, 97.5^{\circ} \mathrm{W}\right)$ in north-central Oklahoma. First, Fig. 2a shows, as a dotted blue curve, the time evolution of root-zone soil moisture in the grid cell over the course of the year 2000. For comparison, the heavy blue curve shows the climatology of root-zone moisture obtained from processing the full 38-yr MERRA-2 record. Starting on day 217 (early August) of 2000, the soil moisture dropped significantly and remained low for more than two months. The positions of the vertical black lines, spaced 20 days apart, are in fact defined by the corresponding soil moisture percentiles in Fig. 2b; soil moisture on day 217 is above the 40th percentile, and that 20 days later is below the 20th percentile. Furthermore, Fig. $2 \mathrm{c}$ shows that evaporation during the 20 days prior to day 217 was not inordinately low, whereas that after the second vertical line was close to half the climatological 
(a) Soil Moisture (degree of saturation); Precipitation ( $\mathrm{mm} /$ day)

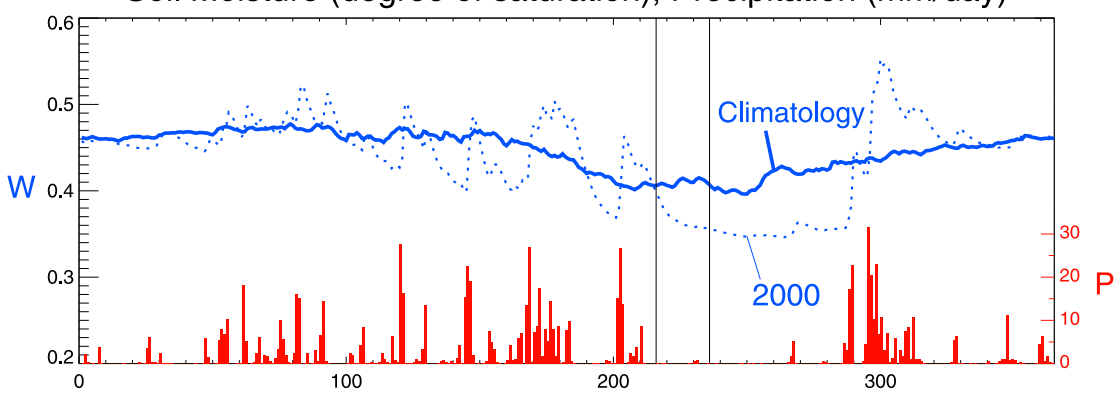

(b)

Soil Moisture Percentile, 2000

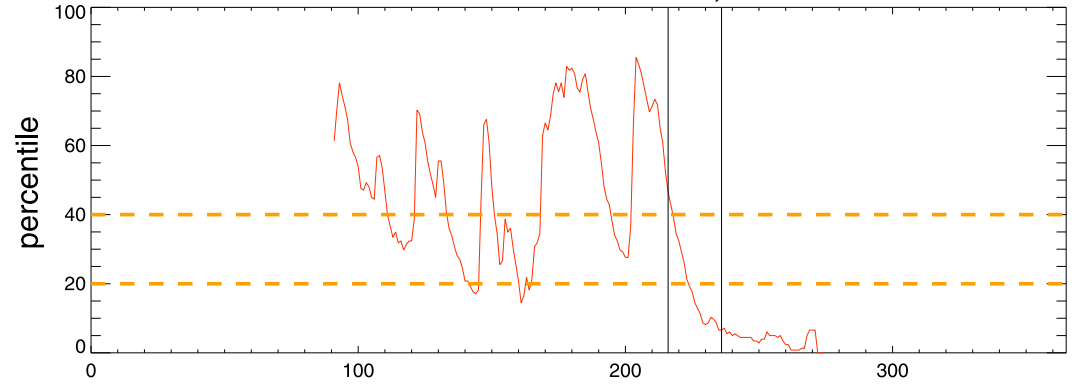

(c)

$\mathrm{ET}(\mathrm{mm} / \mathrm{day})$

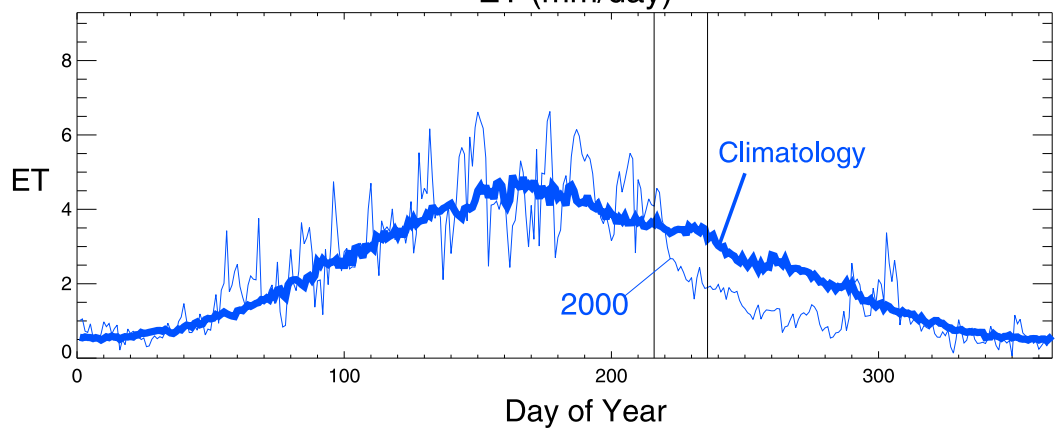

FIG. 2. (a) Climatological annual cycle of root-zone soil moisture (heavy blue curve) at a grid cell centered on $36^{\circ} \mathrm{N}, 97.5^{\circ} \mathrm{W}$ (based on 38 years of MERRA-2 data) along with the time series of soil moisture (dotted blue curve) and daily precipitation (red histogram bars) in that cell for the year 2000. (b) Corresponding time series of soil moisture percentiles during AprilSeptember for the year 2000. The vertical black lines indicate the start and end of the identified flash drought period. (c) Climatological annual cycle (dark blue curve) and 2000 time series (light blue curve) of ET at that grid cell.

value. Thus, by the definition outlined in section $2 \mathrm{~b}$, the period between days 217-236 at this location qualifies as a flash drought event. Note that based on soil moisture percentiles alone, another flash drought might have been identified starting on day 121 . The evaporation decrease associated with this percentile drop, however, was not large enough to reflect stressed surface conditions.

The calculation of $P^{\prime}$ for the identified 20-day flash drought period is straightforward; MERRA-2 data provide the climatological 20-day mean precipitation for the period, and the anomaly from this mean is accordingly computed. As suggested in section 2c, however, the $\mathrm{ET}_{\mathrm{exc}}$ calculation is a bit more involved, as now illustrated.

Each small dot in Fig. 3 represents a single day during days 207-246 (26 July-3 September) of one of the 38 years in the MERRA-2 record for the grid cell in question; the dot is located according to the soil moisture on that day and the concurrent value of ET. Data are binned within soil moisture ranges (with a width of about 0.02 for this example; note that the bin size we use scales with the soil moisture range) to produce the heavy black line, considered here to be the average soil 


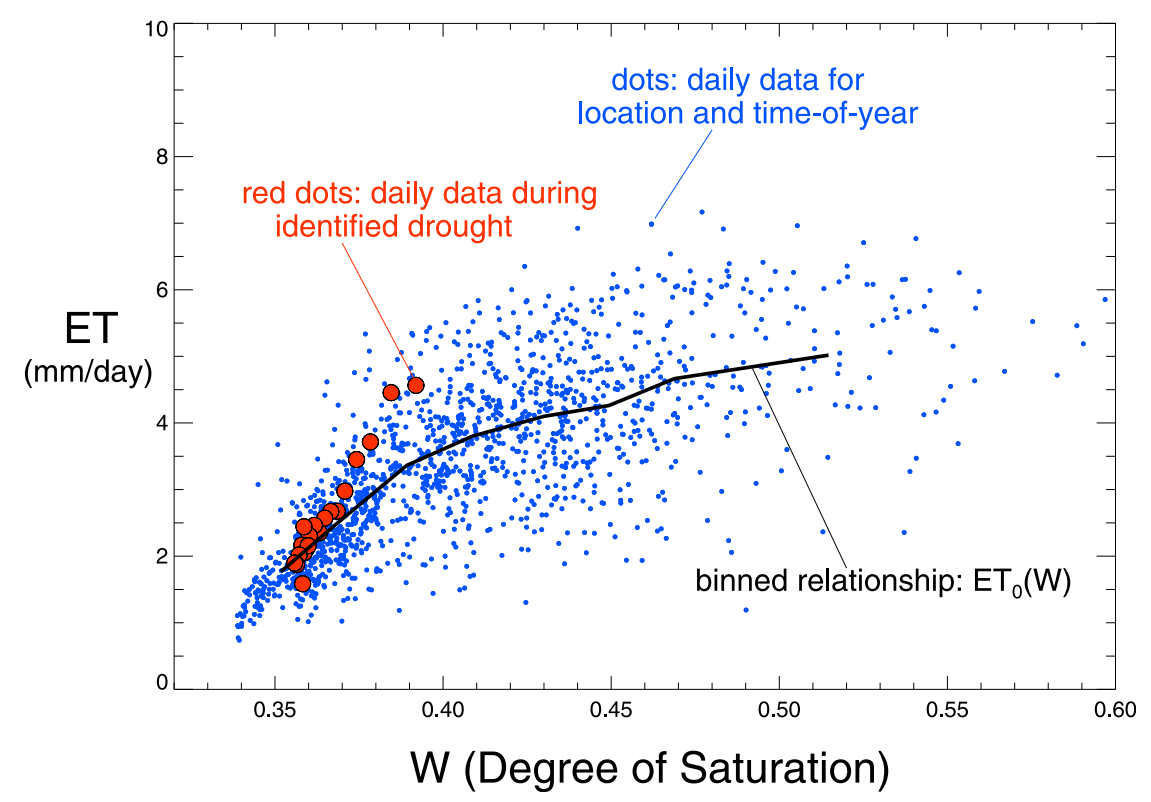

FIG. 3. Scatterplot of ET vs root-zone soil moisture for the grid cell centered on $36^{\circ} \mathrm{N}$, $97.5^{\circ} \mathrm{W}$. Each blue dot represents a single day within $25 \mathrm{Jul}-2$ Sep during 1980-2017 (the days surrounding and including the flash drought period identified in Fig. 2). The particular values for 4-23 Aug 2000 (the actual flash drought period) are marked with red dots. The black line, representing the average relationship, was computed by binning the data within contiguous soil moisture ranges.

moisture-ET relationship for the grid cell and time period in question. We use 10 days before and beyond the 20-day period, amounting to 1520 points for the plot, to double the sample size for determining the time- and location-dependent climatological relationship. Note that the point of the binning procedure is to average out the meteorology-induced variations in ET, which can be large over the 40 days of an individual year even if the soil moisture itself in that year does not change much.

The larger red dots in Fig. 3 represent values contained within days $217-236$ of the year 2000 , that is, during the 20-day drought period identified in Fig. $2 b$. These are generally seen to lie above the average relationship during the 20-day period, especially during the wetter part, which (as seen in Fig. 2c) is the earlier part. Thus, especially during this wetter portion, ET exceeded its climatological values for the soil moistures operating at the time, effectively accelerating the drying of the soil-a mechanism outlined by Otkin et al. (2018). On average for the 20-day period, the excess ET relative to $\mathrm{ET}_{0}(W)$ in Fig. 3 (i.e., $\mathrm{ET}_{\text {exc }}$ ) amounted to $0.28 \mathrm{~mm} \mathrm{day}^{-1}$, a small but not negligible value. Note that $\mathrm{ET}^{\prime}$ for this period (the anomaly relative to the climatological mean, not the anomaly relative to the ET-W relationship) was $-0.83 \mathrm{~mm} \mathrm{day}^{-1}$; we can only capture a positive ET anomaly for forcing this drought by considering explicitly the ET- $W$ relationship.
Figure 4 is constructed from MERRA-2 data at this grid cell. The flash drought identified in Fig. 2 is represented with a large red dot, which is positioned in the plot according to that period's precipitation anomaly $P^{\prime}$ $\left(-2.76 \mathrm{~mm} \mathrm{day}^{-1}\right.$, the ordinate, corresponding to a deficit of $2.76 \mathrm{~mm} \mathrm{day}^{-1}$ ) and evaporation excess $\mathrm{ET}_{\text {exc }}$ $\left(0.28 \mathrm{~mm} \mathrm{day}^{-1}\right.$, the abscissa). Under the assumption (noted above) that precipitation deficit and evaporation excess are the two key meteorological drivers of drought, a simple way to interpret the relative contribution of the latter is to compute:

$$
\text { relative contribution of } \mathrm{ET}_{\mathrm{exc}}=\frac{\mathrm{ET}_{\mathrm{exc}}}{\mathrm{ET}_{\mathrm{exc}}-P^{\prime}} \text {, }
$$

which, for the numbers listed, amounts to about 0.09 . In other words, we can infer that precipitation deficit is responsible for $91 \%$ of this drought, with evapotranspiration excess (the part of the ET anomaly not associated with the soil moisture anomaly) explaining the remaining $9 \%$. It is worth emphasizing here that while $9 \%$ may seem like a small contribution, it may nevertheless have been critical for qualifying this particular event as a flash drought.

The remaining five flash droughts found for the grid cell over the 38-yr period are represented with black squares in Fig. 4. Plugging the various precipitation deficit and 


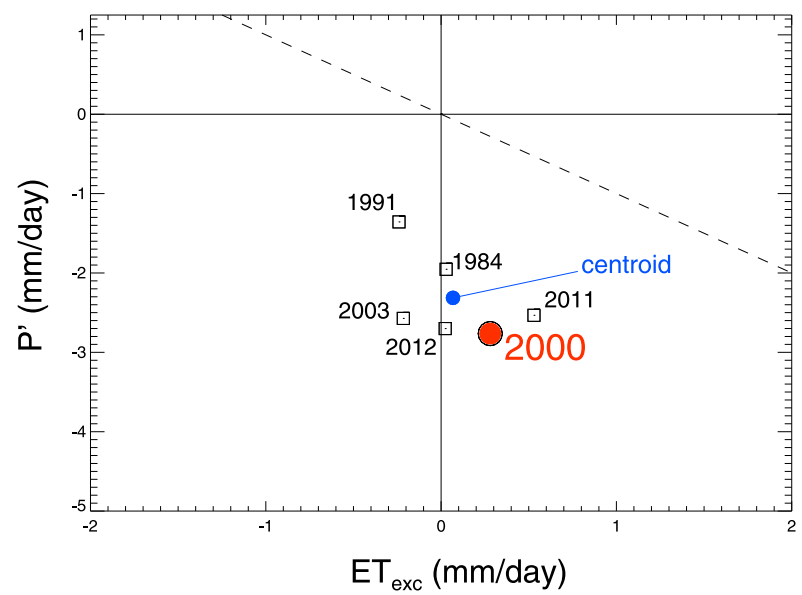

FIG. 4. The relationship between $P^{\prime}$ and $\mathrm{ET}_{\mathrm{exc}}$ for the six flash droughts identified for the grid cell centered on $36^{\circ} \mathrm{N}, 97.5^{\circ} \mathrm{W}$. The red dot indicates the drought considered in Fig. 3. The blue dot, meant to represent an "average" flash drought, is located at the centroid of the six data points.

evapotranspiration excess values into (6) shows that close to $20 \%$ of one of these droughts (that in 2011) was derived from evapotranspiration excess. The flash drought identified for 2012 corresponds to that highlighted for the general area by Otkin et al. (2018); according to our analysis, precipitation deficit accounted for about $99 \%$ of this flash drought. For the flash droughts in 1991 and 2003, ET during the 20-day flash drought period fell below the climatological ET-versus- $W$ relationship, meaning that while ET was still acting to dry the soil during these droughts, the drying was below what would normally (i.e., climatologically) occur for the soil moistures in play. Thus, the reduced ET during the 1991 and 2003 droughts effectively acted to mitigate the strengths of these droughts. (For context, the evaporation anomalies $\mathrm{ET}^{\prime}$ of all six droughts - that is, the ET anomalies relative to climatology rather than to the ET- $W$ relationshipranged from -0.5 to $-1.4 \mathrm{~mm}_{\text {day }}{ }^{-1}$. Thus, if $\mathrm{ET}^{\prime}$ rather than $\mathrm{ET}_{\text {exc }}$ were used in (6), the relative contributions of evapotranspiration to flash drought generation would be even smaller.)

The six flash droughts identified for the region are somewhat scattered across the plot, though all lie well below the dashed (1:-1) line, indicating that precipitation deficit is the dominant contributor to each drought. The centroid of the six drought symbols is plotted as a blue circle. We interpret the centroid as representing, in a sense, the average contributions of $P^{\prime}$ and $\mathrm{ET}_{\mathrm{exc}}$ to the area's flash droughts. Based on the position of this centroid and using the logic behind (6), we can say that precipitation deficits are responsible, on average, for $97 \%$ of flash droughts at this grid cell, whereas ET, which sometimes enhances and sometimes

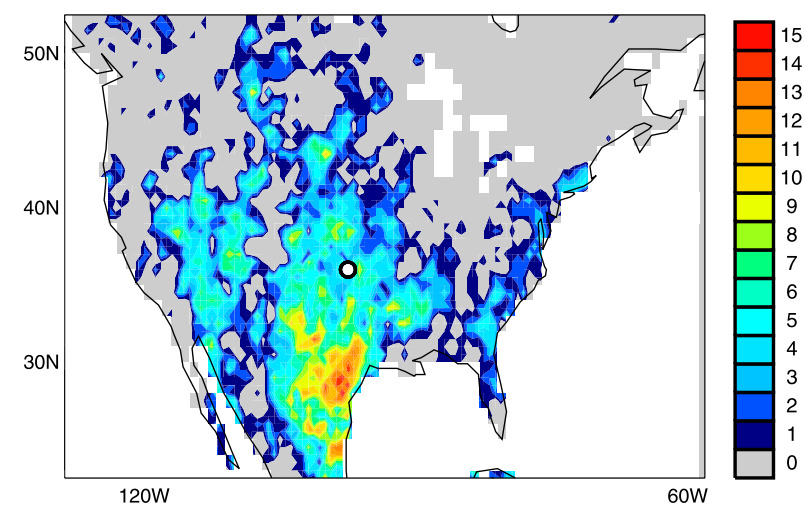

FIG. 5. Number of flash droughts identified from MERRA-2 data during the period April-September of 1980-2017. In regions shaded gray, no 20-day period in the warm-season MERRA-2 record satisfied the flash drought criteria defined for this analysis. The white dot indicates the location considered in the example analyzed in Figs. 2-4.

mitigates these droughts, is on average responsible for the remaining $3 \%$.

\section{b. Flash drought frequency}

Figure 5 shows, as a function of location, the number of flash droughts identified during the warm season (April-September) across all years of the 1980-2017 MERRA-2 period. (Each day between 1 April and 10 September is considered a potential start date for a flash drought; again, identified flash droughts are not allowed to overlap in time.) The first feature to notice is the lack of any flash droughts over about half of the continental United States (CONUS). Most of the droughts are seen in the southern Great Plains (notably Texas, with up to 14), with relatively few identified to the north and in the eastern and far western portions of the continent.

In considering this plot, it must be kept in mind that the numbers shown depend in large part on the specifics of the flash drought definition outlined in section $2 \mathrm{~b}$. A less (more) stringent criterion for percentile change would naturally lead to higher (lower) numbers and greater (reduced) spatial coverage. Nevertheless, we can assume that for reasonable specifications of our thresholds, the general patterns in Fig. 5 would be retained. This assumption was tested with a few variants of the basic definition: we tried setting the percentiles at the start and end, respectively, of a flash drought to the 35th and 25th percentiles and to the 40th and 10th percentiles, and after reverting to the original percentile requirements, we tried changing the prior and subsequent 20-day ET criteria to be $95 \%$ and $75 \%$ of the climatological ET instead of $80 \%$ and $60 \%$. These different test definitions led to overall patterns very similar to those in 


\section{\# of flash droughts by month, 1980-2017}
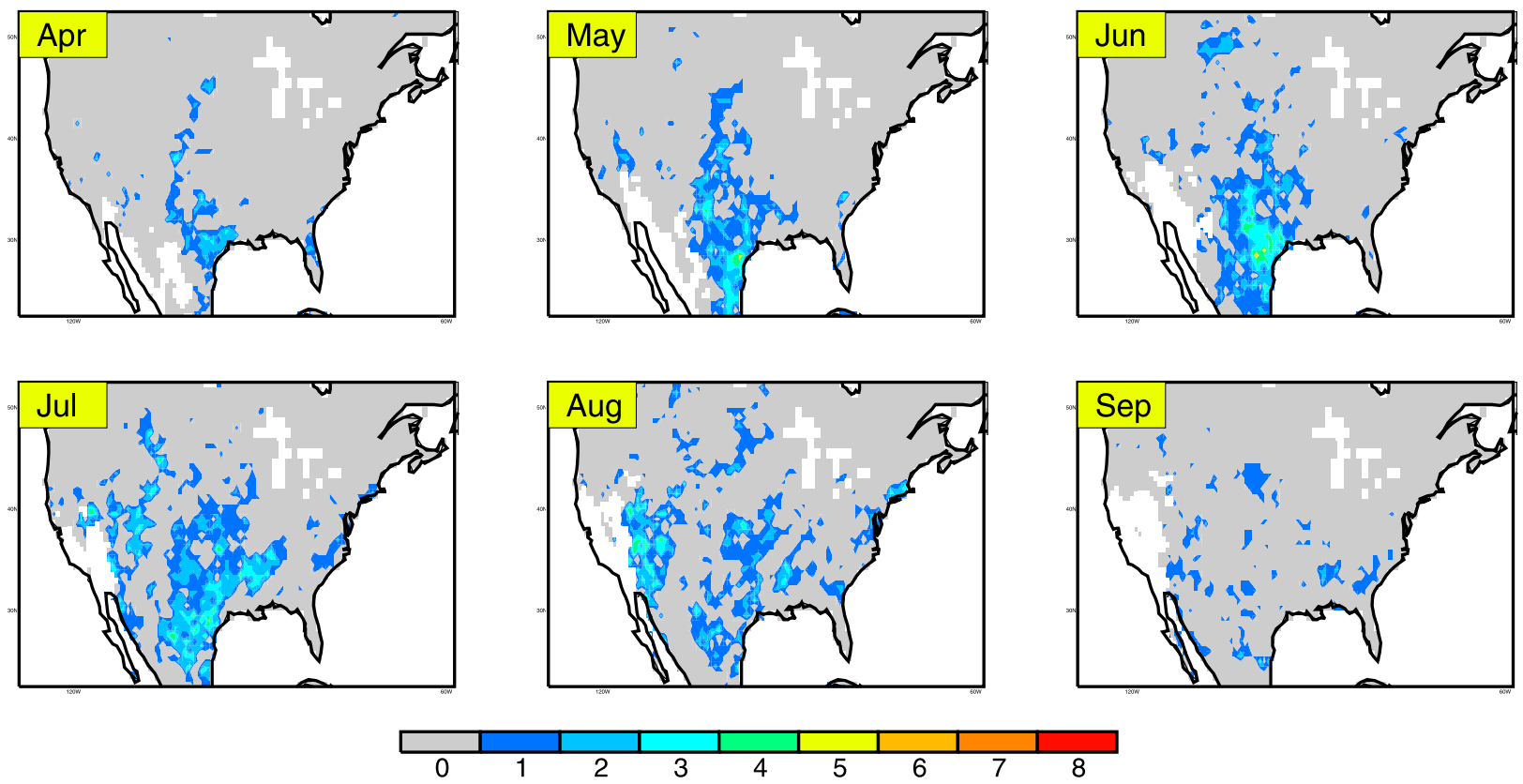

FIG. 6. As in Fig. 5, but for each warm-season month considered separately. Also, in these panels, areas for which the climatological evapotranspiration is below $0.5 \mathrm{~mm}$ day $^{-1}$ for the month—and thus for which flash drought identification is not allowed—are whited out.

Fig. 5 (not shown). Of course, a flash drought definition with a very different character may produce somewhat different patterns.

Figure 6 shows how the flash drought numbers vary with month. The droughts in the Texas region occur most frequently in June, and the southern Great Plains in general see most of their flash droughts during MayJuly. According to MERRA-2 and our specific flash drought definition, these droughts are relatively rare in the transition months of April and September. Note that in Fig. 6, we white out areas that do not satisfy, on average for that month, our flash drought requirement (section 2b) that climatological ET exceed $0.5 \mathrm{~mm} \mathrm{day}^{-1}$. Although this criterion has a large impact in the far west, over most of the continent shown it does not come into play. The reduction of flash droughts in April and September therefore does not simply follow from the imposed minimum climatological ET threshold.

\section{c. Relative contributions of precipitation and evapotranspiration to flash drought}

To examine the importance of evapotranspiration anomalies to flash drought generation, we compute $P^{\prime}$ and $\mathrm{ET}_{\mathrm{exc}}$ for each flash drought at each grid cell, find the associated flash drought centroid for the grid cell as in Fig. 4, and thereby determine an average fractional contribution of $\mathrm{ET}_{\mathrm{exc}}$ to flash drought at the grid cell [i.e., $\overline{\mathrm{ET}_{\mathrm{exc}}} /\left(\overline{\mathrm{ET}_{\mathrm{exc}}}-\overline{P^{\prime}}\right)$, where the overbar here refers to an average over the identified flash droughts]. Figure 7a shows how these fractional contributions vary across CONUS. Toward the west, ET anomalies tend on average to reduce the magnitude of a flash drought, whereas along a small north-south swath in the central Great Plains, ET anomalies contribute, on average, roughly $10 \%$ to flash drought generation. The salient message from the figure, however, is simply that (on average) ET contributions to flash drought are small relative to those of precipitation deficits-any impact of ET is quite secondary to that of precipitation itself.

The red dots in Fig. 3 suggest that $\mathrm{ET}_{\text {exc }}$ might tend to be larger at the very beginning of an identified 20-day flash drought period, when the soil is still relatively wet. To examine this, and to exemplify further the wide variety of drought-relevant calculations made possible by reanalysis data, we show in Fig. $7 \mathrm{~b}$ the average (centroid-based) $\overline{\mathrm{ET}_{\mathrm{exc}}} /\left(\overline{\mathrm{ET}_{\mathrm{exc}}}-\overline{P^{\prime}}\right)$ values computed when only the first 5 days of each identified 20-day flash drought period go into computing $\overline{\mathrm{ET}_{\text {exc }}}$ and $\overline{P^{\prime}}$. The values of $\overline{\mathrm{ET}_{\mathrm{exc}}} /\left(\overline{\mathrm{ET}_{\mathrm{exc}}}-\overline{P^{\prime}}\right)$ at drought onset are clearly higher than those for the full 20-day flash drought period, particularly in the aforementioned north-south swath in the center of CONUS, with average values reaching 0.4 in some grid cells. Low values are still seen, however, outside of this swath.

Of course, individual droughts can differ from each other substantially, even at a single location. To construct 
(a) Ave. $\mathrm{ET}_{\text {exc }}$ contribution to flash drought

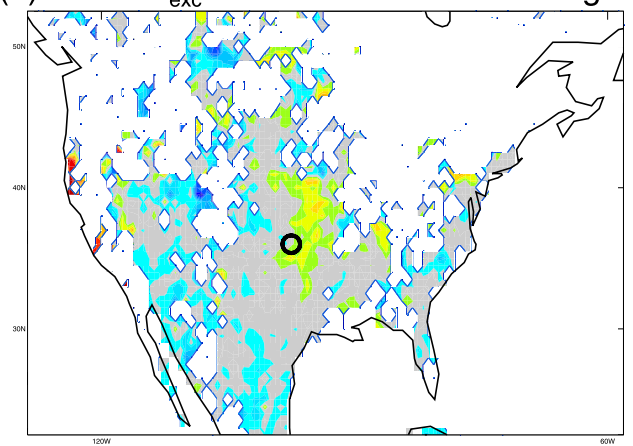

(c) Max. $\mathrm{ET}_{\text {exc }}$ contribution to flash drought

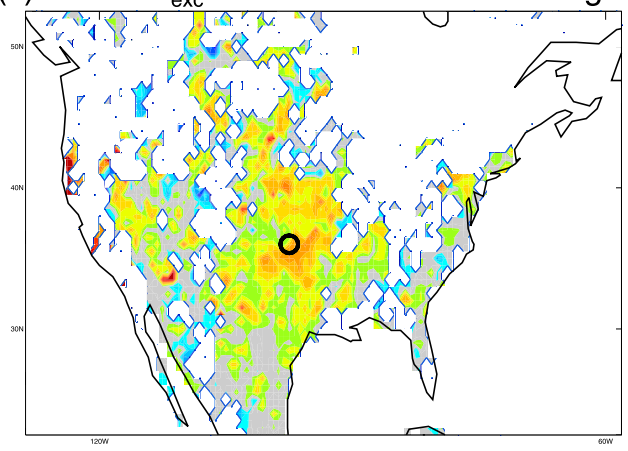

(b) Ave. $\mathrm{ET}_{\text {exc }}$ contribution during first 5 days

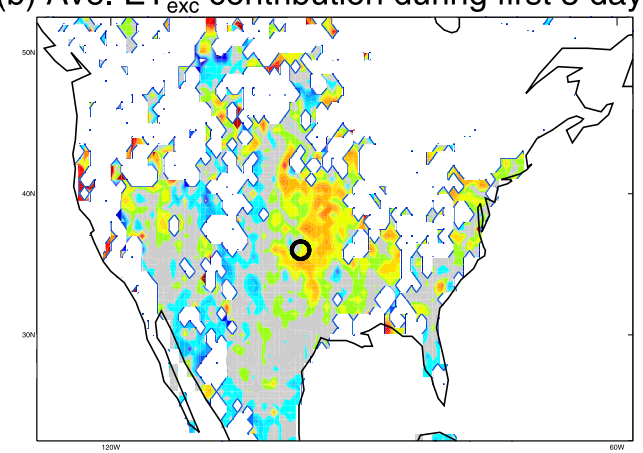

(d) Max. $\mathrm{ET}_{\text {exc }}$ contribution during first 5 days

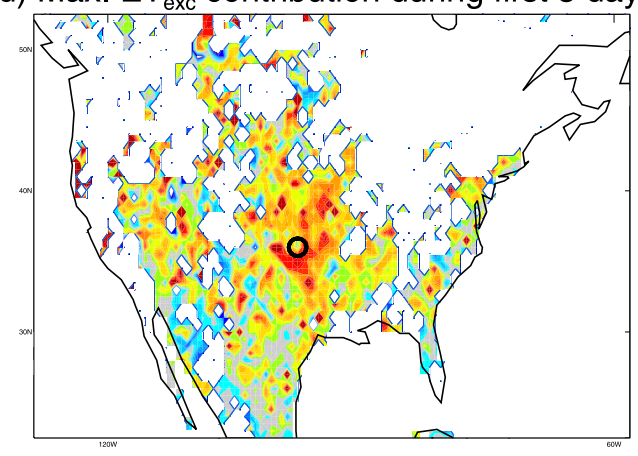

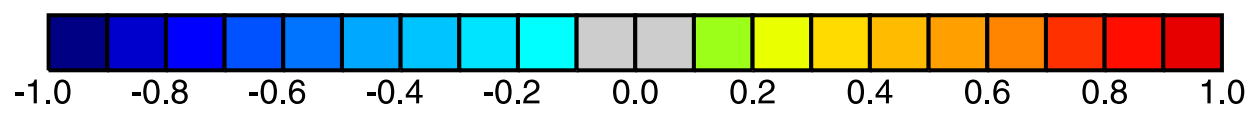

FIG. 7. (a) Map of $\overline{\mathrm{ET}_{\mathrm{exc}}} /\left(\overline{\mathrm{ET}_{\mathrm{exc}}}-\overline{P^{\prime}}\right)$, that is, the average fractional contribution of ET anomalies (relative to the climatological ET- $W$ relationship) to flash droughts at a grid cell. (b) As in (a), but for $\overline{\mathrm{ET}_{\text {exc }}}$ and $\overline{P^{\prime}}$ computed over only the first 5 days of the identified (20-day) flash drought period. (c) Composite map of the maximum singledrought $\mathrm{ET}_{\mathrm{exc}} /\left(\mathrm{ET}_{\mathrm{exc}}-P^{\prime}\right)$ value obtained across all individual flash droughts at a grid cell. (d) As in (c), but for $\mathrm{ET}_{\text {exc }}$ and $P^{\prime}$ computed over only the first 5 days of the single identified (20-day) flash drought. The open black circle in each map indicates the location considered in the example analyzed in Figs. 2-4.

Fig. 7c, we examined separately the individual flash droughts identified at each grid cell and found the particular drought for which $\mathrm{ET}_{\text {exc }}$ played the largest relative role for the full 20-day drought period. We then plotted at that grid cell the value of $\mathrm{ET}_{\mathrm{exc}} /\left(\mathrm{ET}_{\mathrm{exc}}-P^{\prime}\right)$ for that particular drought. For example, for the grid cell examined in Fig. 4, we plotted in Fig. 7c a value of about 0.2 , corresponding to the value noted above for the 2011 flash drought. A sizable fraction of CONUS, again centered on a swath down the center of the continent, has indeed experienced flash droughts for which the $\mathrm{ET}_{\mathrm{exc}}$ contribution was high, sometimes upward of $30 \%$. Note, however, that even for these select droughts, the importance of precipitation deficits remains dominanta flash drought (as defined here) does not occur unless precipitation is suitably deficient.

Figure $7 \mathrm{~d}$ provides another composite map based on the same droughts used to produce Fig. 7c; here, though, as in Fig. $7 b$, the time-averaging for $\mathrm{ET}_{\text {exc }} /\left(\mathrm{ET}_{\mathrm{exc}}-P^{\prime}\right)$ occurs over only the first 5 days of the identified 20-day flash drought periods. (Again, we want to see if the impact of ETexc is noticeably larger at the onset of the drought.) The use of an individual drought and a shorter averaging period at each grid cell leads to increased noise. Clearly, though, during the onset (first 5 days) of many of these particular droughts, evapotranspiration excess can be said to dominate over precipitation deficit in drying the soil.

The select subset of flash droughts examined in Fig. 7c was also used to construct Fig. 8, which shows the corresponding anomalies of incident shortwave radiation and 2-m air temperature during the 20-day period that produced each of those droughts. (This again is a composite map; by construction, the anomalies plotted at different grid cells come from different time periods.) We examine these two fields because they can be particularly strong drivers of ET anomalies; at a given soil moisture, evapotranspiration might be expected to 


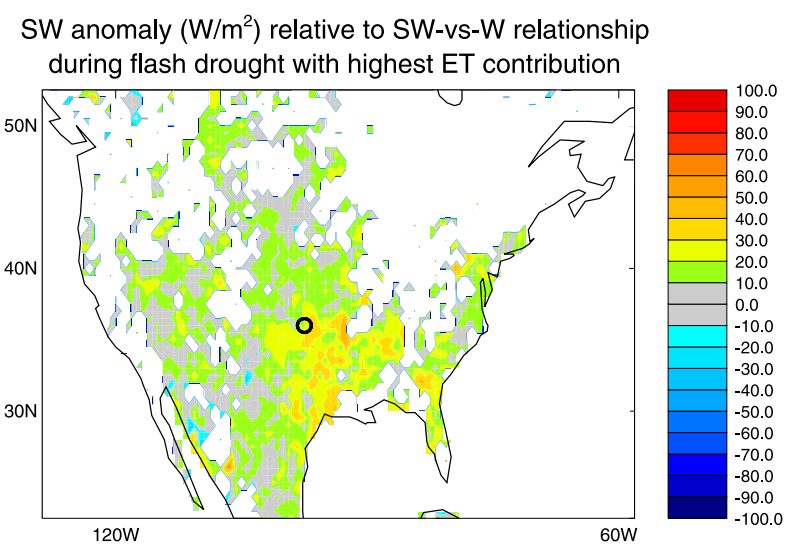

T2M anomaly $\left({ }^{\circ} \mathrm{K}\right)$ relative to $\mathrm{T}-\mathrm{vs}-\mathrm{W}$ relationship during flash drought with highest ET contribution

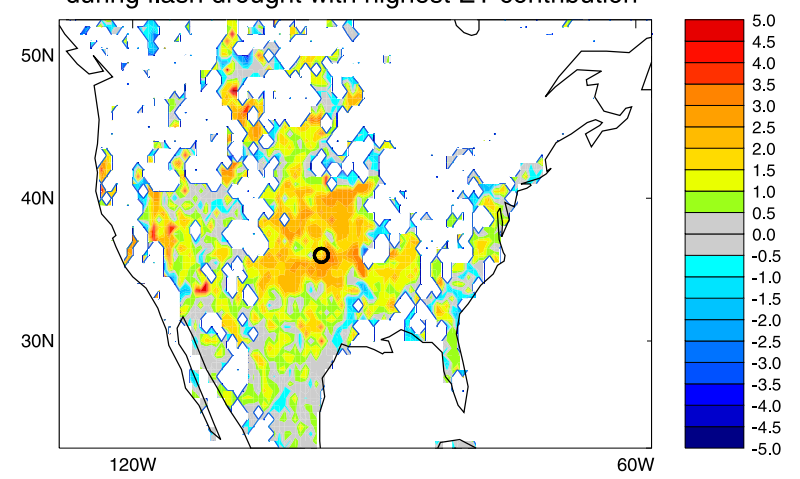

FIG. 8. (a) Composite map showing, at each grid cell, the incoming solar radiation anomaly $\left(\mathrm{W} \mathrm{m}^{-2}\right)$ experienced during the 20-day flash drought period for which $\mathrm{ET}_{\mathrm{exc}} /\left(\mathrm{ET}_{\mathrm{exc}}-P^{\prime}\right)$ is highest (i.e., for which ET had the largest relative impact on the formation of the drought). (b) As in (a), but for 2-m air temperature (K). The open black circle in the maps indicates the location considered in the example analyzed in Figs. 2-4.

exceed the climatological ET- $W$ relationship exemplified in Fig. 3 when either the incident shortwave radiation is higher than normal (e.g., due to reduced cloudiness) or the overlying air temperature is higher than normal (e.g., due to the advection of remote warm air into the region). Two other potentially important drivers, humidity and wind speed, are not considered here.

Because air temperature itself varies strongly with soil moisture, with drier soil moistures inducing higher temperatures through reduced evaporative cooling, we compute air temperature anomalies here using the strategy used above for evapotranspiration anomalies (Fig. 3). That is, we determine a gridcell-specific and time-of-yearspecific climatological relationship between air temperature and soil moisture and then determine all temperature anomalies relative to that climatological relationship. This effectively allows us to consider air temperature anomalies beyond those simply induced by the aforementioned feedback associated with evaporative cooling.
For completeness we also compute shortwave radiation anomalies using this approach, though the connection between shortwave radiation and soil moisture is much weaker.

Figure 8 shows clearly that shortwave radiation and air temperature anomalies tend to be positive during those flash droughts identified as having particularly large positive contributions from $\mathrm{ET}_{\mathrm{exc}}$. Thus, for such droughts, the ET anomalies have a reasonably clear external source. Obviously shortwave radiation and air temperature anomalies are not independent, as the former could induce the latter; even so, the patterns in Fig. 8 suggest that anomalies in the two fields have different areas of impact, with shortwave radiation anomalies being more important toward the southern United States and air temperature anomalies being more important in the center of CONUS.

For additional context, consider the 1991 and 2003 droughts in Fig. 4, that is, the two droughts whose magnitudes were mitigated rather than enhanced by $\mathrm{ET}_{\text {exc }}$. These two droughts turn out to be characterized (not shown) by negative temperature anomalies relative to the locally fitted soil moisture-versus-temperature relationship. Note, however, that the temperature anomaly relative to climatology itself was positive for both droughts ( 0.7 and $1.8 \mathrm{~K}$ for 1991 and 2003, respectively). We interpret this as meaning that these two positive temperature anomalies relative to climatology are responses of the atmosphere to the dry soil moisture conditions rather than drivers of the drought. The reasoning is simple: the fitted soil moisture-versus-temperature relationship provides the land feedback-induced temperature associated with a given soil moisture, so that if the actual temperature lies above (below) this value, the meteorological component of the temperature forcing is anomalously high (low). Though this may be an oversimplification, we assume temperature to be a driver of drought only if the meteorological component is anomalously high. It is naturally important to determine whether temperature is a driver or a response when quantifying drought drivers. As noted in sections $1 \mathrm{~b}$ and $2 a$, the reanalysis data are imperfect; nevertheless, they are well suited to making such a distinction.

\section{d. Northern Hemisphere analysis}

MERRA-2, of course, provides data across the globe. The above analysis focuses on CONUS, a region that features strong climatic variations in conjunction with dense measurement networks across a large continental span. Here we extend the analysis to the Northern Hemisphere, with the caveat that in many areas, the precipitation rates and associated soil moisture percentiles underlying the drought calculations will generally be much more uncertain due to sparser rainfall gauge coverage. The results, though, should still be reliable in 
(a)

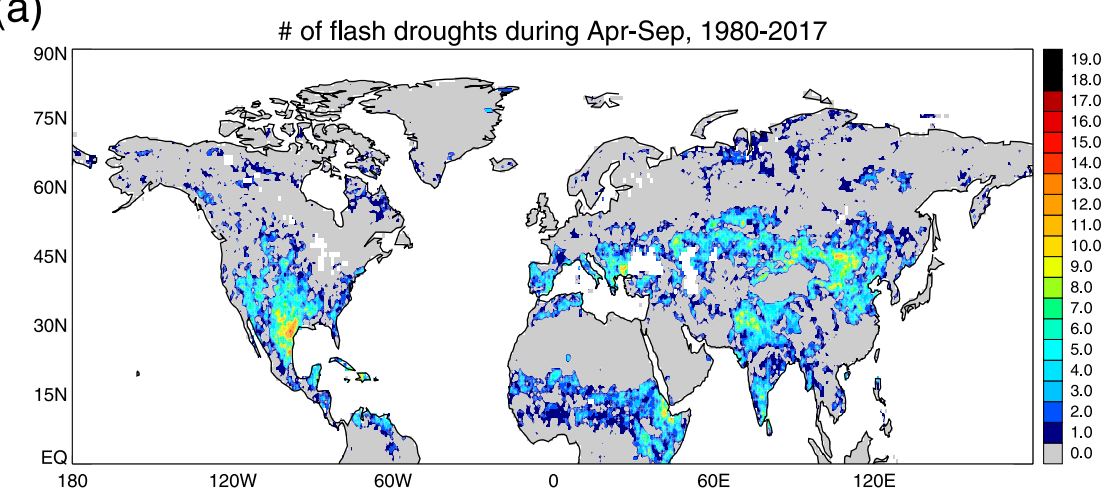

(b)

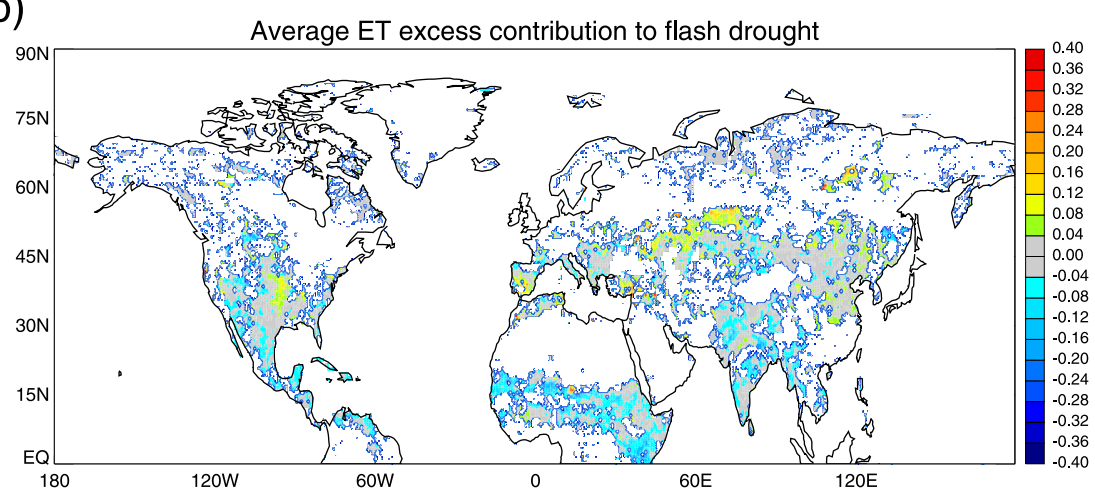

(c)

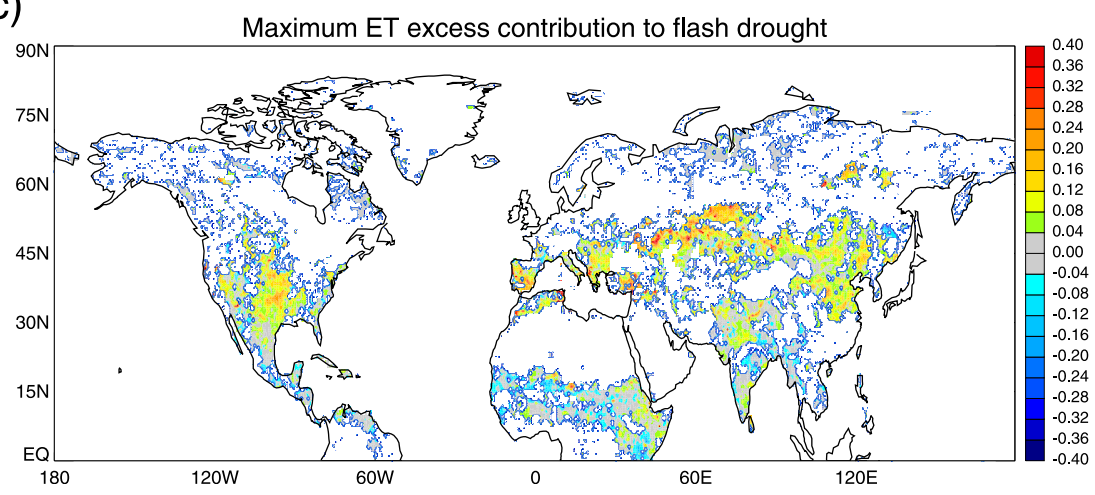

FIG. 9. (a) As in Fig. 5, but for the entire Northern Hemisphere. (b) As in Fig. 7a, but for the entire Northern Hemisphere. (c) As in Fig. 7c, but for the entire Northern Hemisphere.

places where gauge coverage is reasonably high, such as in Europe, parts of central Asia, and western China (see, e.g., Koster et al. 2016, their Fig. 2).

Figure 9a provides, for the Northern Hemisphere, the total flash drought count for April-September of 19802017. Flash droughts are relatively plentiful along an east-west swath that spans Eurasia, starting from southern Europe and continuing to northern China. Flash droughts are also seen in northern and southern India and across the Sahel to the Horn of Africa. Note that across the globe, flash droughts are largely limited to transition zones between dry and wet areas. This is, in part, by construction-as noted in section $2 b$, we use a minimum ET criterion to eliminate from consideration any droughts occurring in very dry areas. The absence of flash droughts in wet areas presumably relates to our imposed requirement that ET show a strong reduction (indicating moisture stress) after the flash drought period; in wet areas, soil moisture at the 20th percentile may still be wet enough to produce a near-climatological ET. 
Figure $9 \mathrm{~b}$ shows the ratio $\overline{\mathrm{ET}_{\mathrm{exc}}} /\left(\overline{\mathrm{ET}_{\mathrm{exc}}}-\overline{P^{\prime}}\right)$ across the Northern Hemisphere, that is, the average relative contribution of 20-day $\mathrm{ET}_{\mathrm{exc}}$ to flash droughts at each grid cell. The largest region for which the average ratio is positive is in central Asia, just north and to the northeast of the Caspian Sea. In contrast, ET anomalies appear to mitigate flash drought strength across the Sahel and in India. When only one flash drought is considered at each grid cell-that is, the individual drought that produced the highest $\mathrm{ET}_{\mathrm{exc}} /\left(\mathrm{ET}_{\mathrm{exc}}-P^{\prime}\right)$ ratio in the cell, as used in the construction of Fig. 7c-the higher values found in central Asia are amplified considerably (Fig. 9c). In central Asia, ET is responsible for more than $30 \%$ of the strength of some flash droughts.

\section{Summary and discussion}

The MERRA-2 reanalysis dataset allows a comprehensive analysis of soil moisture and how it relates to various meteorological forcings. Using a specific quantitative definition of flash drought (adapted from Ford and Labosier 2017) and applying it to MERRA-2 soil moisture data, we identified a number of flash drought events in North America and across the globe, and we then analyzed those flash droughts in terms of the precipitation deficits and evapotranspiration excesses that produced them. Unique to this analysis is the approach used to divide an ET anomaly into two separate components: the anomaly associated with the contemporaneous soil moisture anomaly (through a fitted ET-W relationship), and the ET excess $\left(\mathrm{ET}_{\mathrm{exc}}\right)$, that is, the anomaly determined by conditions, mainly meteorological (warm temperatures, increased incident radiation, etc.), unrelated to soil moisture variations. It is this second component-representing the external or remote drivers of ET that do not reflect a local land-atmosphere feedback - that we compare to precipitation deficit for purposes of flash drought attribution. (Note that if we had instead used the ET anomaly relative to climatology, $\mathrm{ET}^{\prime}$, in our analyses, the contribution of ET to flash drought creation would in fact have been much smaller.) Because ET generally tends to be largest during the warm season, we focus here on the AprilSeptember time period; as a result, there is a possibility that this analysis may have missed some interesting behavior in areas, like California, that have a marked wintertime wet season and thus have ET values that are, correspondingly, relatively high in winter.

We find that under the definition used here, flash droughts do not occur everywhere. Figure 9a in fact suggests that for the period considered, less than half the globe experienced a flash drought during the MERRA-2 period. [Here we can see an impact of the particular flash drought definition we employ-we obtain no flash droughts in the Upper Midwest of the United States, despite one's appearance in 2012 according to an alternative definition (Otkin et al. 2018).] The droughts that do occur under our definition tend to appear in transitional zones between dry and wet regions, though this is partly an artifact of our algorithm's design, which does not allow the identification of flash droughts in very dry areas. In North America, a region centered in Texas features a particularly large number of droughts; across the globe, high numbers are seen in central Asia, northern China, northern India and Pakistan, and the Horn of Africa.

One key result of this study is that while ET excess can be important for specific flash droughts, precipitation deficit almost always has a much greater impact on the reduction of soil moisture during these droughts - a flash drought, as defined here, cannot develop without a particularly large and negative precipitation anomaly. Furthermore, many flash droughts occur without any positive $\mathrm{ET}_{\mathrm{exc}}$ anomaly at all; in North America, for example, about half of the flash droughts in Fig. 5 were induced by precipitation deficits alone. Overall, we find that $\mathrm{ET}_{\mathrm{exc}}$ is at best a secondary contributor to flash drought. In some ways this is at odds with studies in the literature that identify meteorological conditions such as heat waves and high winds as being important or even critical for flash drought development. Our results here reflect in large part the particular flash drought definition and analysis approach we employed (e.g., our use of $\mathrm{ET}_{\mathrm{exc}}$, which is distinct from the oft-considered concepts of evaporative demand or potential evapotranspiration), and thus our analysis should be viewed as complementing, rather than superseding, existing flash drought studies. In any case, even in our analysis, a number of soil moisture decreases in the MERRA-2 record probably would not have been large enough to qualify as flash droughts without the secondary contribution of $\mathrm{ET}_{\text {exc }}$. Figure 6 indeed supports this idea-in North America, more flash droughts occur during the warm summer months, when ET is expected to have the greatest impact, than in the transitional months of April and September.

The secondary role of evapotranspiration anomalies may specifically seem to be at odds with the results of Mo and Lettenmaier $(2015,2016)$, who suggest that heat wave-induced flash droughts are more common than precipitation deficit-induced droughts in areas such as the Ohio Valley (a region, by the way, for which we found no flash droughts). This particular discrepancy, though, is easily explained-although Mo and Lettenmaier (2015, 2016) utilize the term "flash drought" in their analyses, their definition of flash drought is quite different from ours, focusing on short-term drought intensity. Otkin et al. (2018) point to disagreements in the literature 
regarding flash drought definition and propose that the proper definition should in fact focus on the speed of drought development, as considered here. In effect, our study and those of Mo and Lettenmaier (2015, 2016) address different questions, each important in its own right.

Note in any case that when the first 5 days of the flash droughts are considered separately in our analysis (Figs. 7b,d), the importance of $\mathrm{ET}_{\mathrm{exc}}$ increases significantly. ET excess seems to play a particularly strong role at the onset of flash droughts. This facet of drought generation and its implications for early drought warning need to be examined further.

One region that has been discussed in the literature as being particularly subject to heat wave-induced droughts is central Asia. As summarized by Schubert et al. (2014, see their Fig. 1), the connection between droughts and heat waves there reflects in part the central role played by persistent large scale anticyclones in the region; these anticyclones act both to inhibit precipitation by blocking the prevailing westerlies and storm systems and to increase temperature through descending motion and increased insolation associated with clear skies (Buchinsky 1976). Anticyclones also play a role in the development of extended periods of dry hot winds characterized by intense transpiration and rapid wilting of vegetation (Lydolph 1964). Referred to as "sukhovey," these winds have been a major impediment to large-scale sedentary agriculture in central Asia (Sinor 1990). In our analysis, central Asia does show some of the highest relative contributions of ET excess to flash drought (up to $30 \%$ for some individual droughts, as shown in Fig. 9c) seen across the globe, supporting this link. Precipitation deficits, though, still play the largest role, even in this region.

Worth mentioning is how an explicit consideration of runoff generation might affect our results. A negative precipitation anomaly is typically connected to a negative runoff anomaly, and as a result, the net precipitation forcing of the soil column $P^{\prime}-Q^{\prime}$, is typically less than $P^{\prime}$ itself. In other words, if our analysis were to consider $P-Q$ anomalies rather than $P$ anomalies, we might expect a larger relative contribution of $\mathrm{ET}_{\mathrm{exc}}$ to flash drought formation. We purposely focus on $P^{\prime}$ in this analysis, considering it to be the meteorological driver of relevance. To investigate the runoff issue, however, we performed supplemental calculations (not shown) using $P^{\prime}-Q^{\prime}$ in place of $P^{\prime}$. The impact of including the runoff term on the relative contribution of $\mathrm{ET}_{\mathrm{exc}}$ to flash drought turned out to be very small, mostly because flash droughts tend to occur in areas for which runoff ratios $(\bar{Q} / \bar{P})$ themselves are small and because these ratios are particularly small during droughts. That is, our supplemental analysis shows that an explicit consideration of runoff does not change our basic findings.

The determination here that soil water loss during flash droughts is, over the full 20-day period, more strongly affected by precipitation deficit than by ET behavior has a potentially important implication. Given that meteorological conditions associated with higher ET (e.g., large-scale temperature anomalies) may be inherently more predictable at subseasonal-to-seasonal time scales than precipitation itself (e.g., due to deficiencies in existing convective parameterizations), a high relative contribution of $\mathrm{ET}_{\mathrm{exc}}$ to flash drought might have implied a corresponding predictability for flash droughts. Based on the present analysis, however, any such $\mathrm{ET}_{\mathrm{exc}}$-related predictability would appear to be small. Much more work would be needed, of course, to pin down quantitatively the relative impacts of evapotranspiration and precipitation processes on flash drought prediction and how these might vary under alternative definitions of flash drought.

A final yet important issue to consider here is the dependence of our results on the particular modeling system used. As noted in section $1 \mathrm{~b}$, although the modeling components underlying MERRA-2 are state of the art, all models have their individual character, and the ET-W relationship exemplified in Fig. 3 is particularly subject to specific assumptions in the land model regarding the impacts of soil moisture stress on evapotranspiration. It would be valuable to apply our approach to alternate reanalysis products to evaluate the robustness of our results. Note, however, that presumably all reanalysis products would feature an ET- $W$ relationship similar to that in Fig. 3 and that any difference in the absolute magnitudes of soil moisture values between reanalyses is not tantamount to a difference in hydrological behavior (Koster et al. 2009). We strongly suspect that the ET variations around the ET- $W$ relationships in alternate reanalyses would lead to similar conclusions regarding the relative contributions of precipitation deficit and ET excess to flash drought.

Reanalyses, with their comprehensive and self-consistent global data records, are an invaluable laboratory for such analyses. With such data, one can identify flash droughts with a highly quantitative, hydrology- or meteorologybased definition; one can then analyze them extensively in the context of a full suite of flux and soil moisture data. We fully expect that continued studies of reanalysis data will provide additional insights into flash drought behavior.

Acknowledgments. This work was supported by a grant (NA17OAR4310130) from the Modeling, Analysis, Predictions, and Projections (MAPP) program of the 
National Oceanographic and Atmospheric Administration and by the National Climate Assessment. MERRA-2 data were developed by the Global Modeling and Assimilation Office at NASA GSFC under funding by the NASA Modeling, Analysis, and Prediction (MAP) program; the data are disseminated through the Goddard Earth Science Data and Information Services Center (GES DISC).

\section{REFERENCES}

Anderson, M. C., J. M. Norman, J. R. Mecikalski, J. A. Otkin, and W. P. Kustas, 2007: A climatological study of evapotranspiration and moisture stress across the continental United States based on thermal remote sensing: 1. Model formulation. J. Geophys. Res., 112, D10117, https://doi.org/10.1029/2006JD007506.

—_, and Coauthors, 2011: Mapping daily evapotranspiration at field to continental scales using geostationary and polar orbiting satellite imagery. Hydrol. Earth Syst. Sci., 15, 223-239, https://doi.org/10.5194/hess-15-223-2011.

Berg, A., B. R. Lintner, K. L. Findell, S. Malyshev, P. C. Loikith, and P. Gentine, 2014: Impact of soil moisture-atmosphere interactions on surface temperature distribution. J. Climate, 27, 7976-7993, https://doi.org/10.1175/JCLI-D-13-00591.1.

Bosilovich, M. G., and Coauthors, 2015: MERRA-2: Initial evaluation of the climate. NASA Tech. Memo. NASA/TM-2015104606/Vol. 43, 139 pp., https://gmao.gsfc.nasa.gov/pubs/docs/ Bosilovich803.pdf.

Buchinsky, I. E., 1976: Droughts and Dry Winds (in Russian). Gidrometeoizdat, $214 \mathrm{pp}$.

CCSP, 2008: Reanalysis of historical climate data for key atmospheric features: Implications for attribution of causes of observed change. U.S. Climate Change Science Program Synthesis and Assessment Product 1.3, 136 pp.

Dee, D. P., and Coauthors, 2011: The ERA-Interim reanalysis: Configuration and performance of the data assimilation system. Quart. J. Roy. Meteor. Soc., 137, 553-597, https://doi.org/10.1002/qj.828.

Dirmeyer, P. A., R. D. Koster, and Z. Guo, 2006: Do global models properly represent the feedback between land and atmosphere? J. Hydrometeor., 7, 1177-1198, https://doi.org/ 10.1175/JHM532.1.

Draper, C. S., R. H. Reichle, and R. D. Koster, 2018: Assessment of MERRA-2 land surface energy flux estimates. J. Climate, 31, 671-691, https://doi.org/10.1175/JCLI-D-17-0121.1.

Eagleson, P. S., 1978: Climate, soil, and vegetation: 4. The expected value of annual evapotranspiration. Water Resour. Res., 14, 731-739, https://doi.org/10.1029/WR014i005p00731.

Entekhabi, D., and Coauthors, 2010: The Soil Moisture Active Passive (SMAP) mission. Proc. IEEE, 98, 704-716, https:// doi.org/10.1109/JPROC.2010.2043918.

Ford, T. W., and C. F. Labosier, 2017: Meteorological conditions associated with the onset of flash drought in the eastern United States. Agric. For. Meteor., 247, 414-423, https://doi.org/10.1016/j.agrformet.2017.08.031.

Gelaro, R., and Coauthors, 2017: The Modern-Era Retrospective Analysis for Research and Applications, version 2 (MERRA-2). J. Climate, 30, 5419-5454, https://doi.org/10.1175/JCLI-D-16-0758.1.

Hobbins, M. T., A. Wood, D. J. McEvoy, J. L. Huntington, C. Morton, M. Anderson, and C. Hain, 2016: The evaporative demand drought index, Part 1, Linking drought evolution to variations in evaporative demand. J. Hydrometeor., 17, 17451761, https://doi.org/10.1175/JHM-D-15-0121.1.
Kanamitsu, M., W. Ebisuzaki, J. Woollen, S.-K. Yang, J. J. Hnilo, M. Fiorino, and G. L. Potter, 2002: NCEP-DOE AMIP-II Reanalysis (R-2). Bull. Amer. Meteor. Soc., 83, 1631-1643, https://doi.org/10.1175/BAMS-83-11-1631.

Kerr, Y. H., and Coauthors, 2010: The SMOS mission: New tool for monitoring key elements of the global water cycle. Proc. IEEE, 98, 666-687, https://doi.org/10.1109/JPROC.2010.2043032.

Kobayashi, S., and Coauthors, 2015: The JRA-55 Reanalysis: General specifications and basic characteristics. J. Meteor. Soc. Japan, 93, 5-48, https://doi.org/10.2151/jmsj.2015-001.

Koster, R. D., and S. P. P. Mahanama, 2012: Land surface controls on hydroclimatic means and variability. J. Hydrometeor., 13, 1604-1620, https://doi.org/10.1175/JHM-D-12-050.1.

—, M. J. Suarez, A. Ducharne, M. Stieglitz, and P. Kumar, 2000: A catchment-based approach to modeling land surface processes in a general circulation model: 1. Model structure. J. Geophys. Res., 105, 24 809-24 822, https://doi.org/10.1029/ 2000JD900327.

— Z. Zuo, R. Yang, P. A. Dirmeyer, K. Mitchell, and M. J. Puma, 2009: On the nature of soil moisture in land surface models. J. Climate, 22, 4322-4335, https://doi.org/10.1175/ 2009JCLI2832.1.

, L. Brocca, W. T. Crow, M. S. Burgin, and G. J. De Lannoy, 2016: Precipitation estimation using L-band and C-band soil moisture retrievals. Water Resour. Res., 52, 7213-7225, https:// doi.org/10.1002/2016WR019024.

Legler, D., and A. Pirani, 2009: WCRP Drought Interest Group (DIG) coordinates drought research for better prediction of regional drought. CLIVAR Exchanges, No. 51, International CLIVAR Project Office, Southampton, United Kingdom, 4-5.

Lydolph, P. E., 1964: The Russian Sukhovey. Ann. Assoc. Amer. Geogr., 54, 291-309, https://doi.org/10.1111/j.14678306.1964.tb00490.x.

Manabe, S., 1969: Climate and the ocean circulation: I. The atmospheric circulation and the hydrology of the Earth's surface. Mon. Wea. Rev., 97, 739-774, https://doi.org/10.1175/ 1520-0493(1969)097<0739:CATOC >2.3.CO;2.

Mariotti, A., S. Schubert, K. Mo, C. Peters-Lidard, A. Wood, R. Pulwarty, J. Huang, and D. Barrie, 2013: Advancing drought understanding, monitoring, and prediction. Bull. Amer. Meteor. Soc., 94, ES186-ES188, https://doi.org/10.1175/ BAMS-D-12-00248.1.

McCarty, W., L. Coy, R. Gelaro, A. Huang, D. Merkova, E. B. Smith, M. Seinkiewicz, and K. Wargan, 2016: MERRA-2 input observations: Summary and assessment. NASA/TM-2016104606, Vol. 46, 51 pp., https://ntrs.nasa.gov/archive/nasa/ casi.ntrs.nasa.gov/20160014544.pdf.

Mo, K. C., and D. P. Lettenmaier, 2015: Heat wave flash droughts in decline. Geophys. Res. Lett., 42, 2823-2829, https://doi.org/ 10.1002/2015GL064018.

— and - 2016: Precipitation deficit flash droughts over the United States. J. Hydrometeor., 17, 1169-1184, https://doi.org/ 10.1175/JHM-D-15-0158.1.

Otkin, J. A., M. C. Anderson, C. Hain, I. E. Mladenova, J. B. Basara, and M. Svoboda, 2013: Examining rapid onset drought development using the thermal infrared-based evaporative stress index. J. Hydrometeor., 14, 1057-1074, https://doi.org/ 10.1175/JHM-D-12-0144.1.

—, M. Svoboda, E. D. Hunt, T. W. Ford, M. C. Anderson, C. Hain, and J. B. Basara, 2018: Flash droughts, A review and assessment of the challenges imposed by rapid-onset droughts in the United States. Bull. Amer. Meteor. Soc., 99, 911-919, https://doi.org/10.1175/BAMS-D-17-0149.1. 
Randles, C. A., and Coauthors, 2016: The MERRA-2 Aerosol Assimilation. NASA Technical Report Series on Global Modeling and Data Assimilation, NASA/TM-2016-104606, Vol. 45, 140 pp.

Reichle, R. H., and Coauthors, 2017a: Land surface precipitation in MERRA-2. J. Climate, 30, 1643-1664, https://doi.org/10.1175/ JCLI-D-16-0570.1.

, C. S. Draper, Q. Liu, M. Girotto, S. P. P. Mahanama, R. D. Koster, and G. J. M. De Lannoy, 2017b: Assessment of MERRA-2 land surface hydrology estimates. J. Climate, $\mathbf{3 0}$, 2937-2960, https://doi.org/10.1175/JCLI-D-16-0720.1.

Rienecker, M. M., and Coauthors, 2011: MERRA, NASA's Modern-Era Retrospective Analysis for Research and Applications. J. Climate, 24, 3624-3648, https://doi.org/10.1175/ JCLI-D-11-00015.1.

Salvucci, G. D., 2001: Estimating the moisture dependence of root zone water loss using conditionally averaged precipitation. Water Resour. Res., 37, 1357-1365, https://doi.org/ 10.1029/2000WR900336.

Schubert, S. D., H. Wang, R. Koster, M. Suarez, and P. Groisman, 2014: Northern Eurasian heat waves and droughts. J. Climate, 27, 3169-3207, https://doi.org/10.1175/ JCLI-D-13-00360.1.
- , and Coauthors, 2016: Global meteorological drought: A synthesis of current understanding with a focus on SST drivers of precipitation deficits. J. Climate, 29, 3989-4019, https:// doi.org/10.1175/JCLI-D-15-0452.1.

Schwingshackl, C., M. Hirschi, and S. I. Seneviratne, 2018: A theoretical approach to asess soil moisture-climate coupling across CMIP5 and GLACE-CMIP5 experiments. Earth Syst. Dyn., 9, 1217-1234, https://doi.org/10.5194/esd-9-1217-2018.

Seneviratne, S. I., T. Corti, E. L. Davin, M. Hirschi, E. B. Jaeger, I. Lehner, B. Orlowsky, and A. J. Teuling, 2010: Investigating soil moisture-climate interactions in a changing climate: A review. Earth Sci. Rev., 99, 125-161, https://doi.org/10.1016/ j.earscirev.2010.02.004.

Sinor, D., Ed., 1990: The Cambridge History of Early Inner Asia. Cambridge University Press, 518 pp.

Svoboda, M., and Coauthors, 2002: The Drought Monitor. Bull. Amer. Meteor. Soc., 83, 1181-1190, https://doi.org/10.1175/ 1520-0477-83.8.1181.

Wood, E. F., S. D. Schubert, A. W. Wood, C. D. Peters-Lidard, K. C. Mo, A. Mariotti, and R. S. Pulwarty, 2015: Prospects for advancing drought understanding, monitoring, and prediction. J. Hydrometeor., 16, 1636-1657, https://doi.org/10.1175/JHMD-14-0164.1. 